\title{
3 Those Who Can't, Teach: Representations and Challenges of Male Teachers
}

\begin{abstract}
Films and television have provided us with countless images of men who teach. However, research shows that this is at odds with their relative absence from schools and in 'real' classrooms. This chapter explores why these numerous positive media-representations do not necessarily change the perception that teaching is generally seen as a career unsuitable or undesirable for men. Shared ideas of the characteristics that make teaching fulfilling and honourable live side by side in our collective perceptions as a result of media images of inspirational saviours and bumbling educators. Although these positive teacher images may contribute to men's decisions to explore teaching as a career, many of them reconsider when harsh realities show the limits of these idealised portrayals. The strong connection between masculinity and the notion of the modern 'career' also has a role to play in men's absence from a profession that somehow fails to be represented as a 'real' career for men. The necessity and demands of teacher preparation along with greater accountability and less autonomy combine to discourage many of those who consider education from completing programs and entering the field. Teacher educators and others must acknowledge that unrealistic media representations and existing obstacles and challenges do not necessarily have to result in fewer male teachers. An open discussion about what it really means to be a male teacher, with support and rewards, can counter the doubts and help them understand that teaching is a career for competent, caring men.
\end{abstract}

\section{Introduction}

I stand upon my desk to remind myself that we must constantly look at things in a different way

(Dead Poets' Society 1989)

Who doesn't remember Robin Williams as Mr. Keating, the charismatic teacher in Dead Poets' Society, who energises a room full of disaffected boys, inspiring them to - eventually - salute them as their 'captain'? The silver screen (and its smaller cousin, the television) have provided us with countless images of men who teach. Despite their relative absence in schools and in 'real' classrooms, men have been visibly present as teachers in television shows since the 1950s (Dalton 
and Linder 2008, 21). However, as this chapter will show, these numerous mediarepresentations do not necessarily change the perception that teaching is generally seen as a career unsuitable or undesirable for men. Previous research has formulated a number of reasons for men's reluctance to consider teaching as a career choice (such as the low pay-grade, or the doubt expressed over men's lack of caring abilities), but in the sections below I will propose to 'look at things in a different way', and consider how the strong connection between masculinity and the notion of the modern 'career' also has a role to play in men's absence from a profession that somehow fails to be represented as a 'real' career.

Images such as those of the fictional Mr. Keating are important in reflecting on the representation of teaching as a profession and career because, as various researchers have pointed out, film and television programs that include teacher characters have an impact on society's perceptions of educators (Ambrosetti 2016; Fisher, Harris and Jarvis 2008; Rich 2016). These representations can help encourage individuals to pursue a teaching career or reinforce a stereotype that teaching is a low-status low-ability occupation for men who have limited choices. Media images are important texts that help us construct concepts about the world. Dalton (2017b) describes film in popular culture as an "important and often overlooked source of social knowledge” (3), and in my study I will rely on Dalton and Linder's (2008) work on repeated patterns of representation in films and television programs with teacher characters to focus particularly on how men who teach are pictured in these media. I will reflect on the returning portrayals of 'Good' and 'Bad' teachers in the ways in which they represent men and bring these images into a conversation with not only existing research on men's presence (or more often absence) in the teaching profession, but also with the experiences and remarks of a group of men enrolled in certification programs at a small private liberal arts college.

In bringing together an analysis of mediatised representations and the experiences of 'real' (prospective) men in teaching roles, this article examines the image of men who choose teaching as a career in order to answer two main questions. Firstly, it asks how teaching is represented as a 'career' in film and television and in society at large and how the intrinsically gendered notion of 'career' is applied to the teaching profession. Secondly, it attempts to show how teachers' education training - in which institutionalised 'credentials' are seen as an important part of the teacher's career path - enters into a difficult dialogue with cultural images of both the 'Good' and 'Bad' teacher particularly when men enter their programmes.

In what follows, I first describe common representations and understandings of teaching as a career: the first section does so in a general social sense, the second section focuses on representations of teaching as a career for male characters in movies and television series, using Dalton's 'Hollywood model' as 
an organising framework. Based on these two introductory sections, the text interweaves (mediatised) representations, experiences, and expressed discourses on choosing teaching as a career in order to examine the ways in which these representations and realities influence each other. In the third section I introduce the results of a small study using written assignments and reflections along with selected interviews and discuss whether media representations of male teachers play a role in prospective teachers' career decisions and their perception of self. In the fourth and final section, I examine how the cultural images conveyed through the 'Hollywood model' influence development of professional identity for male preservice teachers. The text concludes by describing how media portrayals of men teachers can impact and shape the realities of teaching as a career path for men and describes current issues in helping prospective men teachers do a better job of integrating their perceptions of themselves as the teachers to which they aspire while reconciling it with the realities of the work.

\section{Is Teaching a (Desirable) Career?}

Teaching as a career for both genders is on the decline in the United States. The number of bachelor's degrees conferred in education declined by 15 percent between 2005 and 2006 and 2014 and 2015, while the number of bachelor's degrees conferred across all other major fields increased over that period (Will 2018). Since 2006, the overall number of bachelor's degrees awarded by US colleges and universities has increased by 29 percent, but education has seen a historic decrease of 19 percent, resulting in the lowest number of education graduates since 1986 (Nietzel 2019). In a 2016 national survey of college freshmen, the number of students who say they will major in education has reached its lowest point in 45 years at about 4 percent (Flannery 2016). Despite predictions that a shortage of teachers is a looming crisis, the numbers indicate that the demand is not enough to entice young people to enter the profession (Rich 2014; Sutcher, Darling-Hammond and Carver-Thomas 2016).

For men in particular, teaching as a career choice has been in decline for much longer. The history of the 'feminisation' of teaching is well-documented globally, showing that the increasingly prevalent idea that teaching was akin to 'caring' and therefore intrinsically feminine, made it less attractive as a career for men from the nineteenth century onward (Brophy and Good 1973; Drudy 2008; Strober and Tyack 1980; Wong 2019). Griffiths (2006) examined the complexity of this issue. She explored "different and competing understandings of 'feminization"” as referring to both the numbers of women in teaching as well as the culture 
associated with women (387). Whilst the popularity of teaching as a career for men in the United States waxed and waned throughout the twentieth century - with the space race and the opportunity to coach in school athletics drawing them in, and educational reforms toward higher bureaucracy pushing them out - they have remained a minority among teachers, particularly in primary teaching. The National Centre for Education Statistics (2018) compared characteristics of teachers over a period from 1999/00 to 2015/16. There was a 27 percent increase in the total number of teachers. However, the number of male teachers decreased. Despite the increase in elementary teachers by 19 percent, the number of male teachers at that level decreased from 11 percent to 10 percent. The total number of secondary teachers increased by 37 percent, but the number of male teachers at that level dropped from 43 percent to 36 percent during the same period. This is not true in other traditionally feminised occupations, such as nursing. As Aaron Loewenberg (2017) writes, "[m]ale nurses were as rare as male early educators just a few decades ago. Since 1970, however, the number of male nurses has tripled as the stigma has started to fade and more men have found a growing and vibrant vocation in nursing” (6). While more men are comfortable choosing nursing as a career as perceptions of the work shift, there has not been a similar change in education, where the number of men has been fairly static or decreased.

This seems to be at least partly due to the common representation of teaching as not a profession at all, but rather a simple extension of a number of character traits that are perceived not only as intrinsically feminine but also as 'easy'. This erodes the concept of 'career' as a positive choice for life's work. The idea that 'those who can't, teach' is surprisingly persistent despite the higher standards of preparation and accountability to which today's teachers are increasingly held. As a result of both this 'feminine' nature of the work and low status reputation of teaching, men considering a career in education are often met with either suspicion or encouraged to be 'more ambitious' and seek out a different career. Traits of effective teachers such as empathy and support for socioemotional growth remain seen by parents and society as associated with maternal skills and attributed to women on the basis of biological gender-based traits. Many see teachers as basically babysitters or mothers with curriculum. This perception is not one that is associated with a respected career, especially for men. Various choices and behaviours are used to combat the "persistent image of immaturity and incompetence which perpetuated the notion that teaching was a mere station for men and women intent on bigger and better things in life" (Rury 1989, 11).

Paul Sargent (2001) exposed the difficulties male teachers have negotiating their own masculine identity while carrying out their ideas of effective teaching. These men chose teaching knowing the importance of nurturing and showing care for students' wellbeing as well as their cognitive achievements. However, they 
receive subtle and overt messages about their masculine identity as it relates to their work and choice of teaching as a career (Skelton 2003). A male teacher who enacts 'softer' traits he sees as a necessary part of his role may find himself under increased scrutiny and suspicion (Haase 2008; Sargent 2005). His very success as a teacher may in fact challenge traditional notions of both masculinity and ambition. His classroom behaviour may be in direct opposition to standard perceptions of masculinity in which men are expected to be strong, unemotional, sensible and pragmatic. Paradoxically, perceived natural masculine traits may be seen as positive in terms of discipline. Male teachers are often given unruly or problem students based on an assumption that they will be more of a disciplinarian and better equipped to handle these students, who are often boys (Hjalmarsson and Löfdahl 2014). Men get mixed messages as to how they must behave in such a gendered career. The male teachers in Sargeant's study spoke about the blurry line between subtle and overt messages, and between demands and expectations. Male teachers thus find themselves in a dilemma with few options.

This idea of questioning the choices of men to choose a career that is focused on work with children is deeply embedded in the school culture and difficult to change. This is directly related to changing norms for masculinity (Jones 2007; Kalokerinos, Kjelsaas, Bennetts and von Hippel 2017; Malaby and Ramsey 2011). At a time when social roles are shifting for parents to include stay-at-home fathers and calls are being made to help boys form less traditional and more inclusive and sensitive perceptions of what it means to be a man, we still expect male teachers to act in ways that meet traditional ideas of masculinity. Men who elect teaching as a career with a desire to reshape and challenge traditional gender roles for their students through their work may struggle with the responses from parents and administrators and even student themselves (Sargeant 2001, 164). Martino (2008) discussed how the call for more male teachers as role models "forecloses any critical discussion about the dynamics of gender and sexuality sustaining the heteronormative definitions of what constitutes a sex role model and, more specifically, what version of masculinity is being advocated" (194). Male teachers may act in ways that reinforce traditional gender images for boys in order to meet the expectations of others regarding their career choice. They also live with tensions between their desire to form relationships with their students in order to be effective while staying above suspicion. It is no wonder that a career fraught with such contradictions is not drawing more men. 


\section{Media Representations of Teachers: The Hollywood Model}

Representations of teachers in cinema and on television subscribe to a similar narrative: even though the 'feminine' aspects of the teacher's role are not always underlined, what is repeated across multiple programs and movies is the notion that education is a 'natural' skill, and not a profession requiring specialised knowledge and skills. Media examples abound of individuals who do not hold certification, did not originally plan to become teachers, have never taken a course designed to provide pedagogical knowledge and skills and yet are effective in the classroom. When these men (somehow) obtain positions as teachers, they inevitably succeed in the end. This may be the result of instinctive greatness (such as Jaime Escalante in Stand and Deliver) or inspiring performances (such as John Keating). Improvement is never the result of traditional methods of acquiring pedagogical skills such as professional learning. A striking example - and one often mentioned by pre-service teachers when asked to name films with men who teach - is Kindergarten Cop (Reitman 1998). In one of the few portrayals of a man teaching primary grades, Arnold Schwarzenegger plays Mr. Kimble, who despite his police training and experience is initially unable to handle a classroom of five-year olds. Without any real help or guidance, and no study or coursework, he becomes highly effective and beloved by children and parents. These films support the notion that anyone can teach because it is easy work and can be learned quickly on the job. This is coupled with numerous examples of certified and 'qualified' teachers who are ineffective and boring. No other career is depicted as one in which preparation and study are unnecessary as long as one is inspirational and charismatic.

The Hollywood model (Dalton 2017b) is an overall framework for describing media representations of good and bad teachers. Within this model, the 'Good Teacher' reinforces these views of teaching as a career easily accessible to anyone rather than a choice that demands years of learning and experience. The Good Teacher may have a background in something else, but he is instinctively able to become a great teacher. Mr. Holland in Mr. Holland's Opus enters the profession as a back-up when he cannot find a job. Jaime Escalante in Stand and Deliver leaves his lucrative job in industry to teach poor students in the barrio. Dewey Finn in School of Rock poses as a substitute music teacher at a private school. These films support the notion that anyone can teach because it is easy work and learned quickly on the job. Other traits of the Good Teacher include personal involvement with students and providing a personalised curriculum. These teachers value good teaching and making a difference in the lives of their 
students above all else. They sometimes bend or break the rules, even to the point of losing their job, as in Mr. Keating's case. The cinematic image is of a heroic teacher, often sacrificing his personal life for the needs of his students and the demands of the fight for what is right (Carter 2009; Fisher, Harris and Jarvis 2008; Farhi 1999). While the Good Teacher is an emotionally uplifting character, he is an impossible ideal that helps undermine the career choice for real, ordinary men. A man without the charisma and instinctive skills who studies and comes to teaching through a traditional path must have selected the career as a back-up plan or because of limited ability or options.

Television shows add to the basic images of Good Teachers. Many have mostly male teachers as main characters despite the reality that women are drastically more prominent in actual classrooms (Dalton and Linder 2008, 21). In addition, these portrayals reinforce the idea of teaching as a low paying, low status job for those who are not that smart. Welcome Back, Kotter had Gabe Kotter as a history teacher who returns to his former high school in Brooklyn. No references are made to his teacher preparation and it is unclear if he is certified. He teaches a group of remedial students known as the Sweathogs (a group of which he was a member himself during his years at the school, reinforcing the notion of limited intelligence). Mr. Kotter and his wife struggle financially because of his low salary (making him question his career choice as inadequate to support his family like a real man). The portrayal is realistic, but not one that might inspire other men to seek such a low paying, low status job. Breaking Bad presented a dramatic image of the negative aspects of teaching as a career for men. Walter White, a high school chemistry teacher is "passionate about his subject and eager to engage students with classroom experiments" (Dalton and Linder 2008, 148). He turns to drug dealing because of his need for money in the face of terminal cancer. White is shown taking a demeaning job at a car wash where his students are customers, one of the most tragic media depictions of the impact of low teacher salaries. Even Good Teachers perpetuate negative images of teaching as a career choice for men.

The 'Bad Teacher' is a sharp contrast but just as easily identified. The main fault is lack of effective pedagogy, despite their more traditional path to the classroom that supposedly included meeting high requirements for licensure. In Ferris Bueller's Day Off, Ben Stein portrays an economics teacher whose monotone and boring delivery of content have become a popular culture trope. Bad Teachers are generally more interested in following the rules, which is seen as a bad thing because the rules are not in the best interest of students and learning. They deliver instruction and test students in ways that set them up for failure. They are seen as cogs in a machine, individuals who do not question their effectiveness and remain stagnant across their careers. Bad Teachers rarely have sanctions imposed by 
colleagues, parents or administrators. Students seem to put up with their incompetence or slyly get around their authority. Some Bad Teachers struggle initially, and then become good, even great, teachers. However, this is usually due to some personal epiphany and independent work and rarely due to mentoring or professional development (Ambrosetti 2016; Raimo, Devlin-Scherer and Zinicola 2002).

Media portrayals contribute strong messages to our shared cultural concept of what it means to be a man in education. What are prospective male teachers to make of real and media messages? Teaching as a career choice for men remains a contradiction. As a gendered occupation, concepts of masculinity are at times in opposition to the expected traits of an effective teacher. As a career option, teaching is still questioned when compared to other fields in which more money and more status are the norm. The belief that effective male teachers rely on personal heroism rather than rigorous preparation and high-level knowledge continues the perception that teaching is an easy job for those with less ability and ambition and who are content to settle for this. Anyone can do it, so why would a smart, dynamic man make that choice? Reality and representation create a perception, reinforced through life in schools and media images, that does not make teaching an appealing career choice for men.

\section{Real Men don't Need Credentials?}

The exploratory study discussed below took place at a small private college in the Northeast United States. Enrolment at this institution is approximately 2,400 undergraduate and 2,000 graduate students in over 40 majors and degree programs. The teacher certification program has been preparing teachers at the undergraduate level since the 1980s. Education is not an academic major; students complete a major in another area (such as psychology or history) and also complete coursework and fieldwork to become certified as a teacher. The graduate teacher certification programs began in 1995, and the program graduated over 150 teachers each year at both levels for all secondary content areas as well as elementary and special education and Teaching English to Speakers of Other Languages (TESOL). The number of teachers prepared began to decline during the recession in 2008. Teacher layoffs and changing demographics have impacted teacher education across the state. During the last five years, approximately 50 new teachers have graduated annually at both undergraduate and graduate levels for elementary and secondary licensure. The program was recently revised. There has been an increase in the number of hours of field experience required. Students are placed in area classrooms for practicum experiences 
and opportunities to apply course concepts and skills. The number of credit hours were reduced, and the program is offered in an accelerated (five semester) format. All classes are held in the evening, so that career changers and working adults can access the program. The overall intention is to make the program more attractive and amenable to prospective teachers at all levels, while maintaining the rigorous requirements required for licensure.

During the 2018/19 academic year, data was collected on all students as part of ongoing accreditation efforts. (All teacher education programs in this state are required to hold national accreditation as a measure of quality.) A variety of written data was collected as the basis for faculty discussion as well as assessment of program and course learning outcomes (Peck, McDonald and Davis 2015). These include growth in knowledge base of effective teaching and application of pedagogical skills as well as development of a professional identity. The focus of this surface analysis is presented here. Pre-service teachers are asked to write about their motivation for this career choice and reflect on specific field experiences during courses. All students who elect to leave the program are asked to complete an informal exit conversation regarding the nature of their decision. Qualitative data in the form of essays, assignments, class activities and notes from these conversations were analysed for patterns and issues that should be addressed at the program level. In addition, quantitative data related to retention and attrition were also collected. A number of students left the program for various reasons. While we sought information on all non-completers, we became especially interested in exploring the reasons men left in light of calls for greater male role models and the disparity in numbers in different certification areas.

In Fall 2018, 25 graduate students entered the program (the only start point for graduates). Nine sought secondary level certification (six men) and 16 sought elementary level certification (five men). Over the year, five students left and four of these were men (two elementary and two secondary). Both secondary students obtained teaching positions despite not holding certification. The elementary woman had been working as a teacher assistant in a school, had a problem situation with a student and was forced to resign. One elementary man left because of health reasons. The other left because he felt he had an unrealistic view of the nature and amount of work involved in teaching. The semester began with 11 men out of 25 graduate students (44\%) and ended with seven out of $20(35 \%)$. The program lost five students, but four of the five $(80 \%)$ were men. That same semester, 37 undergraduate students continued in the program as juniors. Nine sought secondary certification (two men) and 31 sought elementary level certification (two men). Over the year, seven students left, all women. These students expressed the same concerns regarding the nature and amount of work as well as alternate career choices. The semester began with 
three men out of 37 undergraduate students (8\%) and ended with three out of 30 (10\%). The program lost seven students, but none were men.

In Spring 2019, 21 undergraduates entered the program. five sought secondary level certification (four men) and 16 sought elementary level certification (two men). Over the year, six students left and four of these were men (one elementary and three secondary). One elementary man left because of health reasons. All three secondary men expressed concerns related to the dissonance between their perception of the work of teaching and their previously held expectations. The semester began with six men out of 24 undergraduate students (25\%) and ended with two out of $18(11 \%)$. The program lost six students, but four of the six $(83 \%)$ were men. The difference overall in undergraduates seeking secondary certification is troubling. In Fall 2019, there will be nine undergraduate (senior) secondary student teachers (two men). In Fall 2020 there will only be two (one man). Overall, 18 of 86 students left the program (21\%) but eight of those 18 were men (44\%).

Qualitative data included application essays that are part of admission to the program, and reflections on field placement experiences. Pre-service teachers (men and women) spent hours each week in classrooms teaching lessons, working with students and observing a host teacher. Assignments asked them to analyse different aspects of teaching and learning and connect concepts from class discussion on learning theory and effective pedagogical skills. Class activities and assignments included two which ask them to reflect on a memorable teacher from their life experience and from media representations and discuss the skills they exhibited in light of the course information. When the data from written activities, journals and essays were examined for patterns (across students of both genders), one overarching teacher archetype emerged: the inspirational teacher. Real teachers were most often described by words related to rigorousness and holding high standards. They demanded excellence, often requiring the students to put in more effort for learning than other teachers. In terms of media images, 61 of all 86 students (71\%) described one or more of the same four film teachers: John Keating from Dead Poets' Society; Jaime Escalante from Stand and Deliver; Glenn Holland from Mr. Holland's Opus; and Erin Gruwell from Freedom Writers. The reasons for the selections were all related to inspiration and the resulting motivation, causing students to want to achieve at a high standard. Descriptions of both real and mediatised teachers were similar. These same sentiments were described in reflections on practicum experience, in which host teachers were described as hard working and dedicated to students, or in some cases, seeming not to care. Finally, a similar theme was evident in application essays, in which prospective teachers expressed a 
desire to make a difference in the lives of their students and being remembered as 'a teacher who helped them be their best'.

This study is limited, since data were collected as part of exploration and formative assessment of a small specific teacher education program undergoing revision and transition. A more focused study with specific research questions related to development of preservice teachers' professional identity is planned based on the research discussed in the following section. These findings do not in any way allow for discernment between men and women pre-service teachers, but it is an interesting preliminary step in exploring possible differences between the two groups in future research. It appears that media images can serve as a tool to interrogate many aspects of teacher identity development and motivation for career choice for both genders. As expressed by others (Carter 2009; Farhi 1999; Shoffner 2016), the heroic teacher found in media representations is often a foundational component of student-teachers' construction of their own burgeoning teacher identity. Although these fictional teachers are unrealistic in many ways, they are also part of the attraction to pre-service teachers of this career, helping them see possibilities and benefits of the profession (Fisher, Harris and Jarvis 2008; Raimo, Devlin-Scherer and Zinicola 2002; Weber and Mitchell 1995). Media representations of male teachers in particular are intended to stick with viewers, and they do. They show the potential of a dedicated adult in the lives of children and young adults. Unfortunately, these images may be part of the dissonance students feel when they encounter the workload of actual teaching. Teacher candidates dream of being that crazy and different kind of teacher; the outside the box thinker dreaming the impossible and making it happen; a teacher no student will ever forget, just like John Keating and Glenn Holland.

\section{Media Influence on Prospective Male Teachers' Professional Identity}

Concerns arise from examining existing research, current statistics, and information from this exploratory study regarding men choosing teaching as a career. Media images of the Good Teachers described in the Hollywood model make teaching seem easy, and dependent on personality and charisma rather than specialised preparation and enormous amounts of difficult work. This appears to contribute as a factor to the limited number of men who choose teaching as a career. Even those who do may not always recognise the influence these images have on their expectations, and the tensions they feel when the 
reality is not what they anticipate. Film teachers, especially men, provide indelible role models (Kirby 2016). Mary Dalton (2017a) states, “[t]he educators we've seen on-screen shape our expectations of actual teachers. And there are more of these characters than real people who have taught us" (1). McGrail and McGrail (2016) state, "[t]he problem with most film characterizations of teachers is that they create unrealisable expectations for real world teachers" (193). Farhi (1999) agrees and argues that, "by forcing them to compete with their cinematic counterparts, the superteacher myth places an impossible burden on real teachers" (157).

It is difficult to define the potential harm of images of teaching as an easy career for those with special qualities and not necessarily credentials. Dead Poets' Society was widely lauded when it was released. George Will (1989) stated:

A prep-school teacher as hero? Keating is heroic, but not in the banal manner of the whip-cracking, death-defying archaeologist [Indiana] Jones. Keating's heroism is in his discipline, the purity of his devotion to his vocation. It is, for him, literally a vocatio, a calling. Language spoken by dead poets calls him. He will summon from some sons of the upper class a sense of the wonderful wildness of life. (74)

No mention is made of John Keating's certification or preparation. The pedagogical skills he employs, such as ripping out the front page of the required text, were most likely not something learned in an accredited teacher preparation program. The image is so indelible that when Williams died in 2014, online and real-world tributes invoked the scene of him standing on a desk reciting Whitman. Jessica Goodman (2014) called it, "the scene that inspired a generation" (1). Cultural images such as this play a powerful part in the formation of this idealised version of the teacher pre-service men in teacher education programs aspire to be. Yet they could not be further from the requirements for licensure and the ongoing struggles that are part of the preparation for these individuals who selected the profession off-screen.

Whitney, Olan and Fredricksen (2013) discussed the overvaluing of practical experience by pre-service teachers. They seem to want concrete strategies that they can use in the classroom immediately without reflection or planning. Attempts to integrate theory and knowledge meet with scorn. Classroom teachers hold the power of authority over research-based texts and assignments in their education program. Like their film role models, they do not see the need for many aspects of the required preparation. They are crafting their professional identity during pre-service courses and field experiences (Ivanova and Skara-Mincāne 2016; Rus, Tomşa, Rebega and Apostol 2013; Timoštšuk and Ugaste 2010). Prospective teachers who select education as a career hold beliefs and self-perceptions about the nature of the work and job satisfaction. 
That may be in opposition to what occurs during their preparation and fieldwork. Hong (2010) explored the interaction between factors such as commitment and emotion over past present and the perceived future of pre-service teachers. Experience changed them. Pre-service teachers who completed student teaching held less idealistic views than those who had not yet been teaching in a classroom. He found that shattered perceptions of what the career genuinely entails may lead to burnout. As he stated, "[t]here might be a fine line between healthy optimism and unrealistic idealism” (1540). Media representations appear to be a factor in tensions that occur throughout teacher preparation.

\section{Conclusion: Let's Go to the Movies}

Teacher educators must accept the impact of media portrayals of male teachers. Whether consciously or not, these images appear to shape the selection and realities of teaching as a career path for men. Teacher preparation programs must make room to address underlying beliefs about male teachers in general and teaching as a career with specialised knowledge and skills for thoughtful intelligent individuals, but one which requires significant preparation and hard work. We must help prospective male teachers do a better job during their training of integrating their perceptions of themselves as the teachers to which they aspire to be while reconciling it with the realities of the work. Use of these media images and structured reflection can help prospective male teachers become a new, more realistic version of the Good Teacher.

Rather than dispute these media images, teacher educators can embrace the dissonance and use it as an opportunity for preservice male teachers to examine their developing professional identity. Several teacher educators have outlined processes by which preservice teachers can use film versions to explore the dynamic conception of what it really means to be a professional in education (Fontaine 2010; Shannon 2016; Triere 2001; Weber and Mitchell 1996). As Farhi (1999) noted about media portrayals of teachers, "[r]emarkably few day-to-day professional details are depicted" (87). Instead of finding fault with media images as appropriate sources for teacher identity, Vandermeersche, Soetaert and Rutten (2013) recommend that teacher education programs use them as a "basis for critical discussion in classes for pre-service teachers" (89). In this way, teacher educators can begin to help pre-service teachers challenge their pre-existing beliefs about teaching as a career and themselves as teachers. Once preservice male teachers' implicit beliefs are made explicit and open to discussion, they can confront the tensions between these beliefs and the reality of becoming a teacher. 
Reflection that raises such conflict is not easy. Ryan and Townsend (2012) note that researchers have often been disappointed by not discovering higher levels of critical reflection by preservice teachers, even when they have used specific structured strategies such as action research and dialogue journals. Delamarter (2015) suggested that teacher preparation programs include "coursebased reflective activities to provide structure and impetus for reevaluating expectations" (1). He provided an analytical framework to use popular teacher films to confront and challenge candidates' expectations of teaching. Selfreflection on a teacher's practice experiences (Delamarter 2015; Whitney, Olan and Fredrickson 2013) with follow-up discussions can help male preservice teachers explore aspects of their developing professional identity that may be hidden below the surface in teacher preparation courses and field experiences. When these men become more aware, they can be better prepared for the realities of the work and perhaps overcome the type of imbalance that can lead to dropping out (Hong 2010).

There is overwhelming evidence that fewer men seek teaching as a career. The numbers are static at best despite changes in the social construction of masculinity to include traits previously ascribed to women, and a call for male teachers as role models. The current teacher shortage should make education an attractive option. However, the hiring of uncertified individuals and alternative routes to licensure continue to promote the perception that teaching is easy, and not a career but a simple job that can be done successfully by anyone (Fraser and Lefty 2018; Redding and Smith 2016; Walker 2016). Recruitment programs for men, especially men of colour, are evolving. Smith, Mack and Akyea (2004) examined African-American male honour students' views of teaching as a career choice, and the results indicate that a "lack of career awareness, lack of positive information regarding the profession, and lack of encouragement are obstacles to students pursuing that interest. Somehow these intervening variables have become effective gatekeepers in restricting African-American male student enrolments in schools of education" (82). Teaching as a career choice for men is a complex issue and will continue to be the focus of recruitment and retention. But it remains to be seen whether efforts to increase the numbers of male teachers will have results.

This paper explored the impact of media images on the selection of teaching as a career and development of a professional identity for male teachers. Teachers are represented in myriad classrooms and media images, and as Mary Dalton (2017a) acknowledged, "[t]he media reinforces the idea that teaching is a dead-end job. Is it surprising that enthusiastic, talented individuals are reluctant to enter the field?" (1). Shared ideas of the characteristics that make teaching fulfilling and honourable live side by side in our collective perceptions as a 
result of media images of inspirational saviours and bumbling educators. Although these positive teacher images may contribute to men's decisions to explore teaching as a career, many of them reconsider when harsh realities show the limits of these idealised portrayals. The necessity for and demands of teacher preparation along with greater accountability and less autonomy combine to discourage many of those who consider education after completing programs and entering the field. Teacher educators must acknowledge that unrealistic media representations and existing obstacles and challenges do not necessarily have to result in fewer male teachers. An open discussion about what it really means to be a male teacher, with support and rewards, can counter the doubts and help them understand that teaching is a career for competent, caring men.

\section{References}

Ambrosetti, Angelina. 2016. "The Portrayal of the Teacher as Mentor in Popular Film: Inspirational, Supportive and Life Changing?" M/C Journal 19(2).

Breaking Bad. 2008-2013. Created by Vince Gilligan. Sony Pictures Television. Television show.

Brophy, Jere E., and Thomas L. Good. 1973. "Feminization of American Elementary Schools." Phi Delta Kappan 54(8): 564-566.

Carter, Catherine. 2009. "Priest, Prostitute, Plumber? The Construction of Teachers as Saints." English Education 42(1): 61-90.

Dalton, Mary M. 2017a. "Film gives teachers credit they’re due.” Winston Salem Journal.

Dalton. Mary M. 2017b. The Hollywood Curriculum: Teachers in the Movies. 3rd ed. New York: Peter Lang.

Dalton, Mary M., and Laura R. Linder. 2008. Teacher TV: Sixty Years of Teachers on Television. New York: Peter Lang.

Dead Poets Society. 2006. Directed by Peter Weir. Burbank: Buena Vista Home Entertainment, DVD.

Delamarter, Jeremy. 2015. “Avoiding Practice Shock: Using Teacher Movies to Realign Pre-

Service Teachers' Expectations of Teaching." Australian Journal of Teacher Education 40(2).

Drudy, Sheelagh. 2008. "Gender balance/gender bias: The teaching profession and the impact of feminisation." Gender and Education 20(4): 309-323.

Farhi, Adam. 1999. "Hollywood goes to school: Recognizing the superteacher myth in film." Clearing House 72(3): 157-159.

Ferris Bueller's Day Off. 1999. Directed by John Hughes. Hollywood: Paramount Pictures, DVD. Fisher, Roy, Ann Harris, and Christine Jarvis. 2008. Education in Popular Culture: Telling Tales on Teachers and Learners. New York: Routledge.

Flannery, Mary Ellen. 2016. "Survey: Number of future teachers reaches all-time low." National Education Association Today. http://neatoday.org/2016/03/15/future-teachers-at-alltime-low/ (accessed December 31, 2018). 
Fontaine, Haroldo A. 2010. "The Power of Film to Educate and Miseducate Pre-Service Teachers: A Phenomenological Analysis of Hidalgo and Cultural Representation of Muslims Post 9/11." Multicultural Education 17(2): 37-43.

Fraser, James W., and Lauren Lefty. 2018. Teaching Teachers: Changing Paths and Enduring Debates. Baltimore, MD: Johns Hopkins University Press.

Freedom Writers. 2007. Directed by Richard LaGravenese. Hollywood: Paramount Pictures, DVD.

Goodman, Jessica. 2014. “Robin Williams And The 'O Captain' Scene That Inspired A Generation.” Huffington Post. https://www.huffpost.com/entry/robin-williams-o-captain _n_5670177 (Accessed July 2, 2019).

Griffiths, Morwenna. 2006. "The feminization of teaching and the practice of teaching: Threat or opportunity?" Educational Theory 56(4): 387-405.

Haase, Malcolm. 2008. “'I don't do the mothering role that lots of female teachers do': male teachers, gender, power and social organisation." British Journal of Sociology of Education 29(6): 597-608.

Hjalmarsson, Maria, and Annica Löfdahl. 2014. "Being caring and disciplinary - male primary school eachers on expectations from others." Gender and Education 26(3): 280-292.

Hong, Ji Y. 2010. "Pre-service and beginning teachers' professional identity and its relation to dropping out of the profession." Teaching and Teacher Education 26(8): 1530-1543.

Ivanova, Ilze, and Rita Skara-Mincāne. 2016. "Development of Professional Identity during Teacher’s Practice.” Procedia - Social and Behavioral Sciences 232(3): 529-536.

Jones, Deborah. 2007. "Millennium man: constructing the identities of male teachers in early years contexts." Educational Review 59(2): 179-194.

Kalokerinos, Elise, Kathleen Kjelsaas, Steven Bennetts, and Courtney von Hippel. 2017. “Men in pink collars: Stereotype threat and disengagement among male teachers and child protection workers." European Journal of Social Psychology 47(5): 553-565.

Kindergarten Cop. 1998. Directed by Ivan Reitman. Universal City: Universal Studios Home Entertainment. DVD.

Kirby, Davina C. 2016. "The influence of teacher media images on professional tteacher identities." PhD diss., University College London.

Loewenberg, Aaron. 2017. "There's as Stigma Around Men Teaching Young Kids. Here's How We Change It.” Slate.com. https://slate.com/human-interest/2017/10/a-male-preschoolteacher-reflects-on-the-stigma-keeping-men-out-of-pre-k-classrooms.html Accessed December 31, 2018.

Malaby, Mark, and Sarah J. Ramsey. 2011. "The dilemmas of male elementary preservice teachers." Curriculum and Teaching Dialogue 13(1-2): 1-17.

Martino, Wayne John. 2008. "Male Teachers as Role Models: Addressing Issues of Masculinity, Pedagogy and the Re-Masculinization of Schooling." Curriculum Inquiry 38 (2): 189-223.

McGrail, J. Patrick., and McGrail, Ewa. 2016. "Why Bad Teacher is a bad movie and where the real crisis is: Implications for teachers and teacher education." In Exploring Teachers in Fiction and Film: Saviors, Scapegoats and Schoolmarms, edited by Melanie Shoffner, 192-202. New York: Routledge.

Mr. Holland's Opus. 1999. Directed by Oliver Wood and Stephen Herek. Burbank: Buena Vista Home Entertainment, DVD.

National Centre for Education Statistics. 2018. "Characteristics of Public School Teachers." Institute of Educational Sciences. United States Department of Education. Last 
modified April 2018. https://nces.ed.gov/programs/coe/indicator_clr.asp (Accessed February 15, 2019).

Nietzel, Michael T. 2019. "Whither the Humanities: The Ten-Year Trend in College Majors.” Forbes. https://www.forbes.com/sites/michaeltnietzel/2019/01/07/whither-thehumanities-the-ten-year-trend-in-college-majors/\#1942cd8864ad (accessed February 15, 2019).

Peck, Charles A., Morva McDonald, and Susannah Davis. "Using Data for Program Improvement: A Study of Promising Practices in Teacher Education." American Association of Colleges for Teacher Education. https://secure.aacte.org/apps/rl/res_get. php?fid=1638\& ref=rl (accessed July 2, 2019).

Rădulescu, Camelia. 2013. "Reinventing Reflective Learning Methods in Teacher Education."Procedia - Social and Behavioral Sciences 78: 11-15.

Raimo, Angela, Roberta Devlin-Scherer, and Debra Zinicola. 2002. "Learning about Teachers through Film." The Educational Forum 66(4): 314-23.

Redding, Christopher, and Thomas M. Smith. 2016. "Easy in, Easy out: Are Alternatively Certified Teachers Turning Over at Increased Rates?” American Educational Research Journal 53(4):1086-1125.

Rich, Motoko. "Why Teachers on TV Have to Be Incompetent or Inspiring." New York Times. https://www.nytimes.com/2016/04/10/opinion/sunday/why-teachers-on-tv-have-to-beincompetent-or-inspiring.html (accessed September 29, 2018).

Rich, Motoko. “Why Don’t More Men Go Into Teaching?” New York Times. https://www.ny times.com/2014/09/07/sunday-review/why-dont-more-men-go-into-teaching.html (accessed September 29, 2018).

Rury, John L. 1989. "Who Became Teachers? The Social Characteristics of Teachers in American History." In American Teachers: Histories of a Profession at Work, edited by Donald Warren, 9-48. New York: Palgrave Macmillan.

Rus, Claudia Lenuţa, Anca Raluca Tomşa, Oana Luiza Rebega, and Livia Apostol. 2013. “Teachers' Professional Identity: A Content Analysis." Procedia - Social and Behavioral Sciences 78: 315-319.

Ryan, Patrick A., and Jane S. Townsend. 2012. "Promoting Critical Reflection in Teacher Education Through Popular Media." Action in Teacher Education 34(3): 239-248.

Sargent, Paul. 2001. Real Men or Real Teachers?: Contradictions in the Lives of Men Elementary School Teachers. Harriman, TN: Men's Studies Press.

Sargent, Paul. 2005. "The Gendering of Men in Early Childhood Education." Sex Roles 52(3-4): 251-259.

Shannon, Patrick. 2016. "Films, Governmentality and Agency in the Struggle over Reading Education." In Exploring Teachers in Fiction and Film: Saviors, Scapegoats and Schoolmarms, edited by Melanie Shoffner, 183-191. New York: Routledge.

Skelton, Christine. 2003. "Male Primary Teachers and Perceptions of Masculinity." Educational Review 55(2): 195-209.

Smith, Vernon G., Faite R-P. Mack, and Stacey Gray Akyea. 2004. "African-American Male Honor Students' Views of Teaching as a Career Choice.” Teacher Education Quarterly 31 (2): 75-88.

Stand and Deliver. 1998. Directed by Ramón Menéndez. Burbank: Warner Home Video, DVD. Strober, Myra H., and David Tyack. 1980. "Why Do Women Teach and Men Manage? A Reporton Research on Schools." Signs: Journal of Women in Culture and Society 5(3): 494-503. 
Sutcher, Lieb, Linda Darling-Hammond, and Desiree Carver-Thomas. A Coming Crisis in Teaching? Teacher Supply, Demand, and Shortages in the U.S. Palo Alto: Learning Policy Institute. https://learningpolicyinstitute.org/product/coming-crisis-teaching (accessed February 15, 2019).

Timoštšuk, Inge, and Aino Ugaste. 2010. "Student teachers' professional identity."Teaching and Teacher Education 26(8): 1563-1570.

Trier, James D. 2001. "The Cinematic Representation of the Personal and Professional Lives of Teachers." Teacher Education Quarterly 28(3): 127-142.

Vandermeersche, Geert, Ronald Soetaert, and Kris Rutten. 2013. "'Shall I tell you what is wrong with Hector as a teacher?' The History Boys, Stereotypes of Popular and High Culture, and Teacher Education." Journal of Popular Film \& Television 41(2): 88-97.

Walker, Tim. 2016. "Hiring Non-Certified Teachers No Way to Address Teacher Shortage, Say Experts." National Education Association Today. http://neatoday.org/2016/03/23/ teacher-shortage-non-certified-teachers/ (accessed December 31, 2018).

Weber, Sandra, and Claudia Mitchell. 1995. That's Funny, You Don't Look Like a Teacher!: Interrogating Images and Identity in Popular Culture. Washington, DC: Falmer Press.

Weber, Sandra, and Claudia Mitchell. 1996. "Drawing ourselves into tteaching: Studying the images that shape and distort teacher education." Teaching and Teacher Education 12(3): 303-313.

Welcome Back, Kotter. 1975-1979. Created by Gabe Kaplan and Alan Sacks. Hollywood: Warner Brothers Television Distribution. Television show.

Whitney, Anne Elrod, Elsie L. Olan, and James E. Fredricksen. 2013. “Experience Over All: Preservice Teachers and the Prizing of the "Practical." English Education 45(2): 184-200.

Will, George. 1989. “O Robin! My Captain!” Newsweek, July 3. http://lexisnexis.com (accessed July 2, 2019).

Will, Madeline. 2018. "Enrolment Is Down at Teacher Colleges. So They're Trying to Change." Education Week. https://www.edweek.org/ew/articles/2018/08/09/enrollment-is-downat-teacher-colleges-so.html (accessed January 15, 2019).

Wong, Alia. 2019. "The U.S. Teaching Population is Getting Bigger, and More Female." The Atlantic. https://www.theatlantic.com/education/archive/2019/02/the-explosion-ofwomen-teachers/582622/ (accessed March 15, 2019). 